\title{
A saúde do trabalhador da saúde: um tema importante para debates
}

O tema Saúde do Trabalhador da Área da Saúde tem sido foco de estudos e discussões no âmbito mundial. Nos últimos anos, a Organização Mundial de Saúde (OMS) tem manifestado preocupações globais relacionadas à carência de recursos humanos na área da saúde bem como à segurança ocupacional e bem-estar dos trabalhadores dessa área.

No Brasil, a configuração da Saúde do Trabalhador se dá diretamente no âmbito do direito à saúde, conforme preconiza a Constituição Brasileira de 1988, sendo de responsabilidade do Sistema Único de Saúde (SUS).

A complexidade do tema requer 0 desenvolvimento de políticas intersetoriais que possibilitem analisá-lo de forma ampla, propiciando o desenvolvimento de ações que atendam ao princípio da integralidade desses trabalhadores. A partir da Portaria GM/MS no 3252 de dezembro de 2009, a Vigilância em Saúde do Trabalhador (VISAT) integra o Sistema Nacional de Vigilância em Saúde com o objetivo de promoção da saúde e redução da morbimortalidade da população trabalhadora. Tal propósito se consolida por meio de ações individuais e coletivas que intervenham nos agravos e nos determinantes de saúde relacionados a riscos ocupacionais tradicionais (físicos, químicos, biológicos, mecânicos, ergonômicos, organizacionais) e a outros determinantes como fatores sociais e econômicos que impactam no estilo de vida, culminando em situações de risco para a saúde e para a vida desses trabalhadores. Em relação a estes últimos, há evidências científicas sobre o estilo de vida inadequado de trabalhadores da área da saúde decorrente do sedentarismo e de hábitos alimentares inadequados, culminando em sobrepeso, obesidade e alterações metabólicas (diabetes mellitus, hipertireoidismo, dislipidemia, entre outros).

Esta edição da Revista Ciência \& Saúde aborda um tópico importante desta temática que é considerado um dos problemas de saúde pública, a obesidade e o sobrepeso, como um importante fator de risco para trabalhadores da área da saúde, reforçando a necessidade de ações motivacionais e de intervenções que visem mudanças no estilo de vida dos mesmos.

Boa Leitura!

Prof . Dr $r^{2}$. Beatriz Sebben Ojeda Diretora da Faculdade de Enfermagem, Nutrição e Fisioterapia da PUCRS 